\title{
The application of instrumentation system on a contactless robotic triage assistant to detect early transmission on a COVID-19 suspect
}

\author{
Niko Azhari Hidayat ${ }^{1}$, Prisma Megantoro², Abdufattah Yurianta ${ }^{3}$, Amila Sofiah ${ }^{4}$, \\ Shofa Aulia Aldhama ${ }^{5}$, Yutika Amelia Effendi ${ }^{6}$ \\ 1,2,4,5,6Faculty of Advanced Technology and Multidiscipline, Universitas Airlangga, Indonesia \\ ${ }^{3}$ Faculty of Science and Technology, Universitas Airlangga, Indonesia
}

\begin{tabular}{l} 
Article Info \\
\hline Article history: \\
Received Feb 14, 2021 \\
Revised Apr 2, 2021 \\
Accepted Apr 27, 2021 \\
\hline
\end{tabular}

Keywords:

Automation

COVID-19

Infectious disease

Microcontroller

Public health

\begin{abstract}
This article discusses the instrumentation system of airlangga robotic triage assistant version 1 (ARTA-1), a robot used as a contact-free triage assistant for Coronavirus disease (COVID-19) suspects. The triage process consists of automatic vital signs check-up as well as the suspect's anamnesis that in turns will determine whether the suspect will get a specific care or not. Measurements of a suspect's vital conditions, i.e. temperature, height, and weight, are carried out with sensors integrated with the Arduino boards, while a touch-free, hand gesture questions and answers is carried out to complete anamnesis process. A portable document format (PDF) format of the triage report, which recommends what to do to the suspect, will then be automatically generated and emailed to a designated medical staff.
\end{abstract}

This is an open access article under the CC BY-SA license.

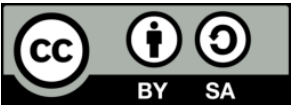

\section{Corresponding Author:}

Prisma Megantoro

Faculty of Advanced Technology and Multidiscipline

Universitas Airlangga

Surabaya, Indonesia

Email: prisma.megantoro@stmm.unair.ac.id

\section{INTRODUCTION}

Coronavirus disease (COVID-19), discovered in 2019, is a disease caused by the severe acute respiratory syndrome coronavirus 2 (SARS-CoV-2) virus. It is highly contagious to human regardless of age [1], but people with weak immune systems, such as the elderly, pregnant women, and young children, have a higher risk of being infected [2]. Researchers found that SARS-CoV-2 can adapt and mutate in the human body, making it highly infectious and the world is currently witnessed its unprecendented transmission rate [3]. As of 24 December 2020, World Health Organization (WHO) reports 79,313,541 confirmed COVID-19 cases worldwide, with a total of 1,742,765 deaths. Meanwhile, according to the International Council of Nurses (ICN), there are nearly 300,000 medical workers are infected with COVID-19 globally [4].

Data collection on early examinations for COVID-19 patients has been done in the referred hospitals throughout Indonesia. The results showed that $28 \%$ of patients were taken with isolative measures, while $62 \%$ of them had not been clearly categorized as people under surveillance or patients under surveillance or people without symptoms [2]. Such an alarming statistic calls upon better data management, especially in handling COVID-19 suspects. Furthermore, limited personal protective equipment (PPE) use by paramedics during initial COVID-19 screening increases the chance of transmissions due to full contacts between 
suspects and medical personnels, compared to other triage processes [5], [6]. Therefore, a contact-free solution, such as the use of teleoperated robots, is urgently needed.

The use of teleoperated robots for medical purposes has been discussed by several reseachers. Chang et al. utilized a robot to do a simple triage on victims of a mass-casualty incident [7]. Tsumura and coworkers also reported a teleoperative robotic platform capable of performing lung ultrasonic scanning for infected patients [8]. To address the anxiety of the frontline paramedics, and most importantly to provide better protection for them, as well as to suppress COVID-19 chains of transmission, herein, we present the robotic triage assistant as a contactless solution for initial COVID-19 screening and further organize patient's classifications.

Innovation is needed to reduce the risk of transmission of the virus from patients to medical personnel. In this research, the innovation is made in a medical assistant robot. This robot is a substitute for medical personnel in carrying out the triage process of each patient suspected of COVID-19. All body condition measurements and triage processes are carried out without contact between the user and the device. The triage results from the robot are used by medical personnel to provide further treatment to users related to handling COVID-19.

\section{RESEARCH METHOD}

This research carried out in several stages; the first was a literature study in the field of instrumentation and public health issues involving doctors who determined which vital signs needed from the users/suspects, as well as the types of questions on the anamnesis process. All of them were built into a reliable system design to carry out and execute user's triage process and meet the medical standards. This medical standart depends on patient's condition which categorized in some indicators.

The built system combined hardware assembly, microcontroller programming to gain access to sensor data collection, and desktop application programming which included interfaces, processing and analyzing data from sensors, anamnesis algorithm, and generating triage reports. Analysis of measurement and detection of each sensor is carried out by comparing the readings with the standards.

\subsection{Anamnesis process}

Anamnesis is an active communication, a form of communication that goes beyond empathic communication, or a dialogue between medical staffs and patients to collect medical history of patients. The purpose of such process is to identify the patient's medical problem and to conduct an appropriate diagnosis [9], [10]. In general, the most common diagnosis done by doctor is performed to action or a mandate from medical personnel. It is the doctor's ability to treat the patient due to insufficient medical knowledge [11] and [12].

\subsection{System design}

Figure 1 shows the system design depicted as a block diagram. This robot system or automation system interacts with the user through different sensors and a liquid crystal display (LCD) to measure the user's body temperature, weight, and height. The temperature reading is carried out using a non-contact MLX90614 type temperature sensor [13], [14], while the weight is quantified using a LCS-2160 type loadcell. A long-distance time-of-flight (TOF) integrated sensor, VL5311x type [15], [16], is employed for measuring the user's height parameter. There are two E18-D80NK adjustable infrared switchs used in here, one is to detect the user's presence and the other is to detect the user's hand swipe when answering questions during anamnesis process.

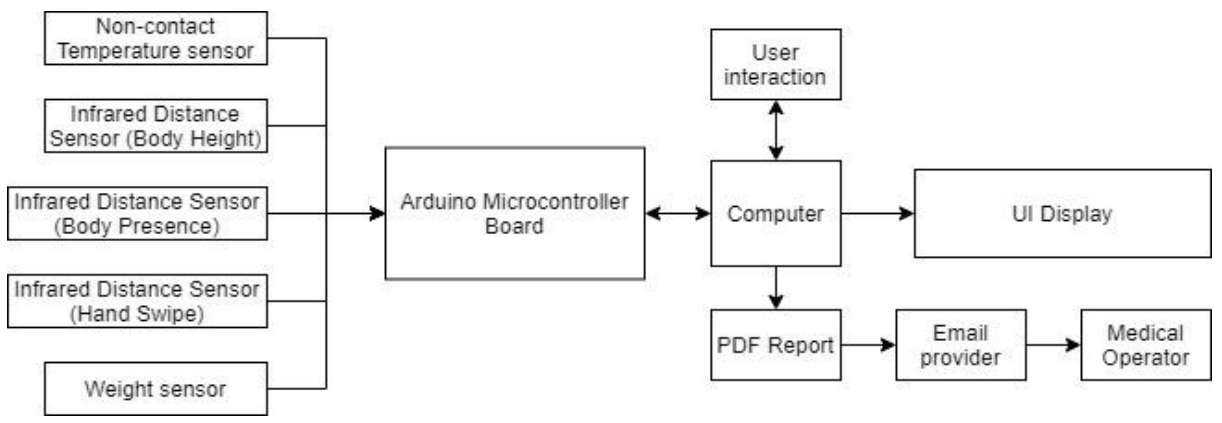

Figure 1. System block diagram 
All sensor readings are regulated by the Arduino microcontroller board to execute user's command created on the computer [17], [18]. It is also used as the core for measuring the vital signs of the user's since its specifications are suitable for real-time processing [19], [20]. Microcontroller boards such as Arduino have also been widely used for instrumentations and control applications in the medical field [21]-[30]. User interactions, triage processes, and report generations are controlled by desktop application, from which a triage report in portable document format (PDF) format will be produced and emailed to the medical operator.

\subsection{Analysis of measurement}

The analysis of the measurements and readings of body parameters was carried out by characterizing the sensors used by considering two factors, namely precision and accuracy. Precision is the factor that shows how consistent an instrument gives a certain value from multiple measurements, which can be indicated by the standard deviation obtained from each measurement. In terms of measurement, accuracy is also the main factor affecting the performance of a sensor. Accuracy shows how precise an instrument in giving a certain expected value obtained from a standardized instrument. The comparison between standard and test values will give a percent error with a limit of $10 \%$ value that indicate how accurate the test measurement is.

\section{IMPLEMENTATION}

The implementation of this research consists of several parts to build airlangga robotic triage assistant version 1 (ARTA-1). An electrical design that shows the wiring connection of all electrical components for both sensors and microcontroller boards. Firmware workflow is embedded on the microcontroller board.

This firmware is made to manage the calibration process, data retrieval, and data transmission for processing in the desktop application. For the anamnesis process, it will be discussed in the desktop application section. Sensor characterization is carried out to ensure the precision and accuracy of the readings on the user's body condition parameters. Figure 2 shows ARTA-1 visualisation as a ready to implemented in both engineering design (Figure 2 (a)) and actual display (Figure 2 (b)).

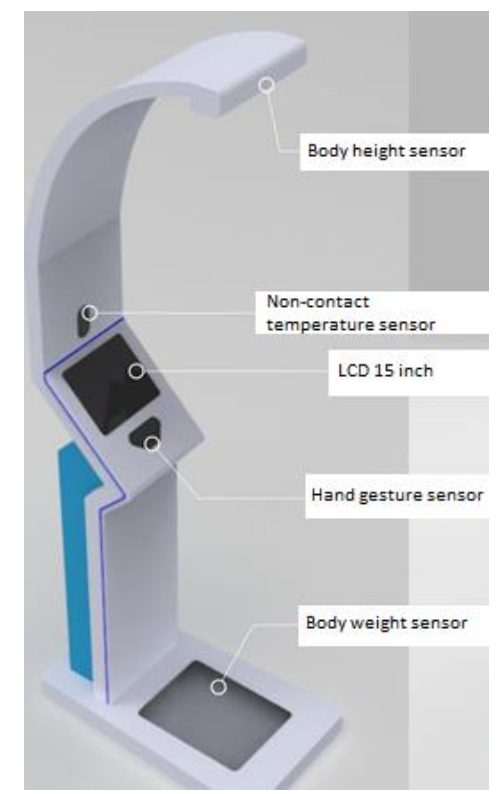

(a)

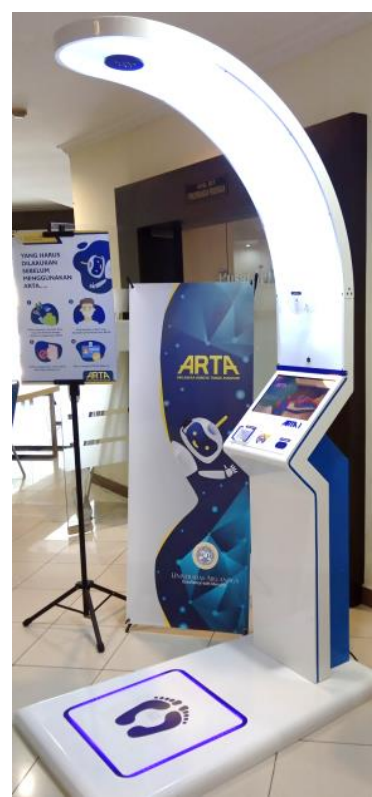

(b)

Figure 2. System design of ARTA-1: (a) engineering design, (b) actual design

Figure 3 shows the functional diagram of the robotic triage assistant system in assisting paramedics to conduct an automatic, non-contact early clinical examinations from COVID-19 suspects. First step is obtain user identity by scanning his/her national identity card. From this step machine got the data of civillian registratrion number, name, birth date, and age. The second step is obtain user's body condition by measuring temperature, body weight, and body height. The third step is doing the anamnestic test, and then calculate the 
binary result of the test. The fourth step is displaying the triage result and create a document, then send it to paramedic for next treatmen.

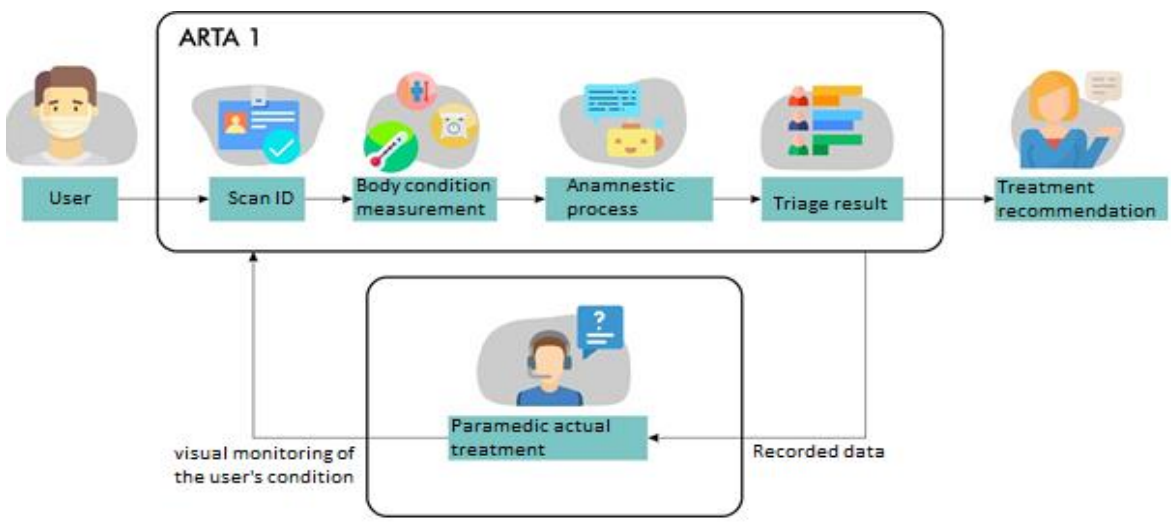

Figure 3. Functional diagram of the system

\subsection{Electrical design}

Figure 4 shows a wiring diagram for an outside computer interface system connected to a microcontroller board. This interface is operated using a $12 \mathrm{~V}, 20 \mathrm{~A}$ power supply in which it also used for sensors, microcontroller boards (Arduino Mega 2560 and Arduino Nano), and a relay. Infrared distance switch sensors used for detecting hand gesture are accessed by an Arduino Nano number 1.

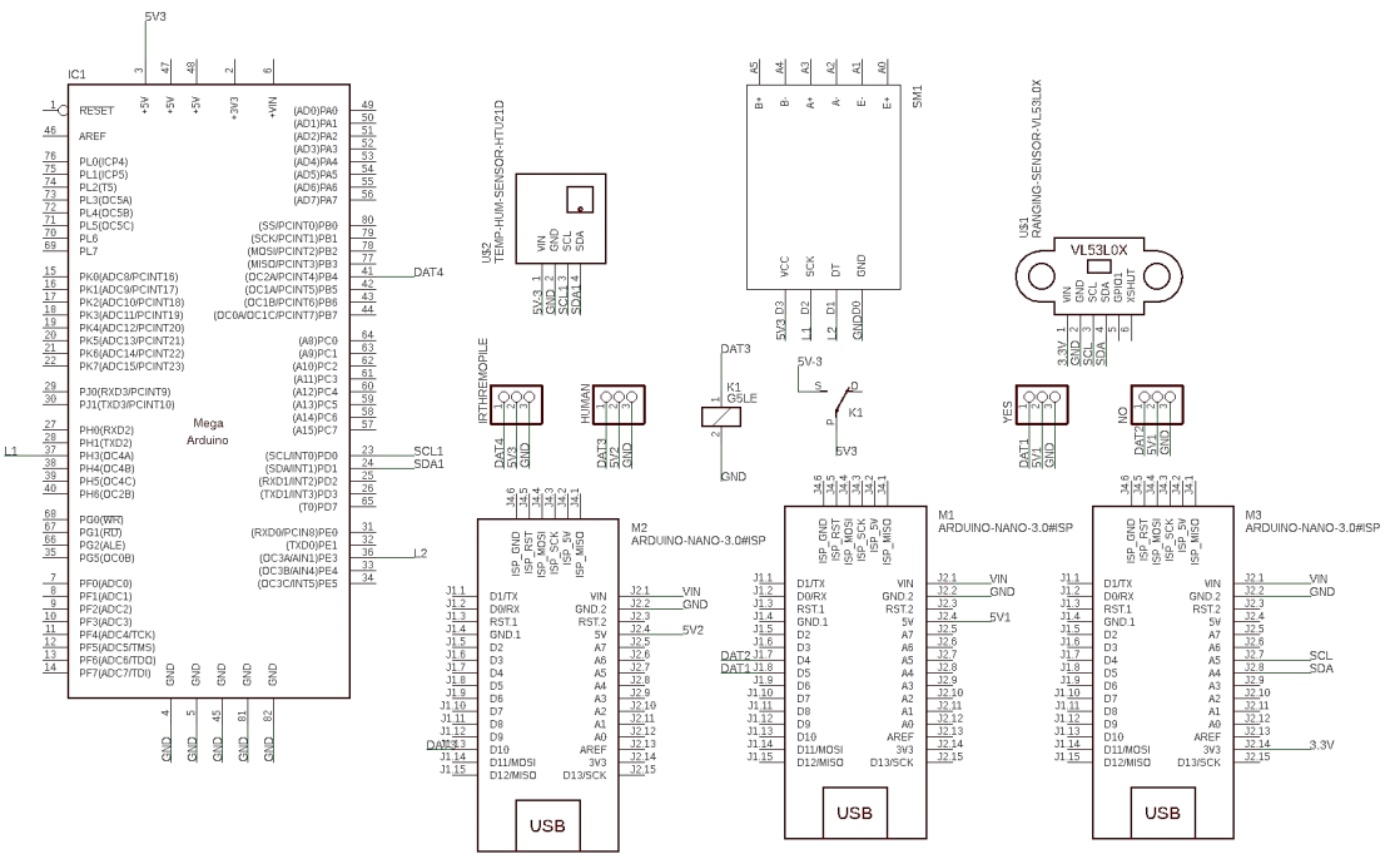

Figure 4. Wiring diagram of microcontroller system interface used in ARTA-1

These sensors are able to detect objects within 3-80 cm distance. Another Infrared distance switch is operated by Arduino Nano number 3 to control the relay where it activates the Thermopile sensor to avoid overheating. The Thermopile sensor uses type of MLX90614, which is an infrared thermometer for non-contact temperature measurements. Both the IR sensitive thermopile detector chip and the signal conditioning ASIC are integrated in the same TO-39 can. Integrated into the MLX90614 are a low noise amplifier, 17-bit analog-to-digital converter (ADC) and powerful digital signal processor (DSP) unit thus achieving high accuracy and resolution. Both the Thermopile sensor and cell module are connected to Arduino Mega. In terms of connection to Arduino Mega, the former uses an inter-integrated circuit (i2c)

The application of instrumentation system on a contactless robotic triage assistant... (Niko Azhari Hidayat) 
connection, while the latter uses data clock communication pins. In the other hand, the load cell has measurement range from 0 to $150 \mathrm{~kg}$. The VL53L1X is a state-of-the-art, time-of-flight (ToF), laser-ranging sensor, enhancing the ST FlightSense ${ }^{\mathrm{TM}}$ product family. It is the fastest miniature ToF sensor on the market with accurate ranging up to $4 \mathrm{~m}$ and fast ranging frequency up to $50 \mathrm{~Hz}$.

\subsection{Firmware for microcontroller}

There are three Arduino Nano and one Arduino Mega 2560 which carry out each measurement or detection of the user's body parameter, Figure 3. Each Arduino board requires firmware designed separately for each measurement, Figure 4. The first detection is carried out in the presence of a user and is controlled by Arduino Nano number 3. As illustrated in Figure 5 (a), if the distance switch detects an object within 30 $\mathrm{cm}$ range, Arduino Nano number 3 will make the relay active. Activation of this relay will start the Thermopile MLX90614 sensor and load cell controlled by the Arduino Mega 2560 with the workflow illustrated in Figure 5 (b).

Height measurement is controlled by Arduino Nano number 2 with the workflow depicted in Figure 6 (a). The anamnesis process using two distant sensors to detect the hand swipe is controlled by Arduino Nano number 1. Its workflow is depicted in Figure 6 (b). If the right sensor indicates LOW logic, then Arduino sends the "NO" command to the application. On the other hand, if the left sensor denotes LOW, then Arduino sends the command "YES" to the application. The command "NO" or "YES" represents the user's hand swipe when answering each question.

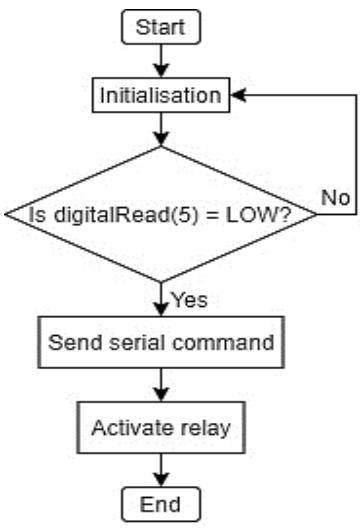

(a)

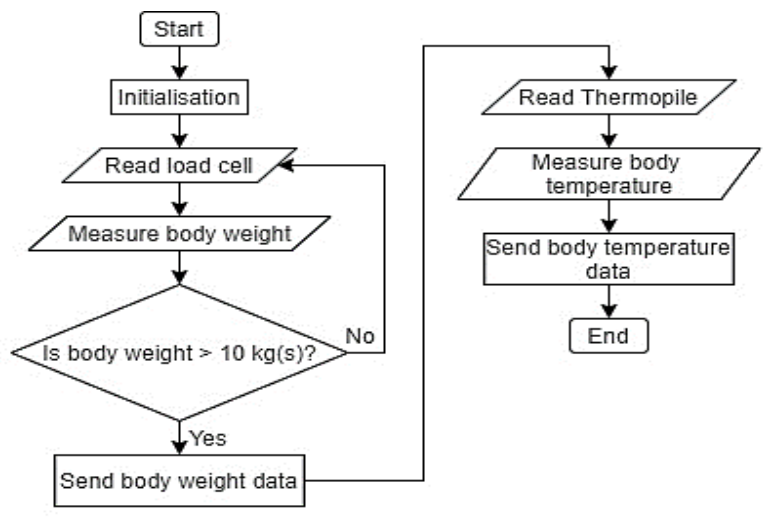

(b)

Figure 5. Work flow diagram for; (a) detecting user in front of monitor screen and (b) measuring body temperature and body weight

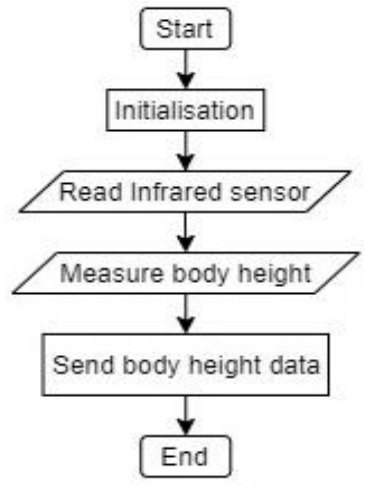

(a)

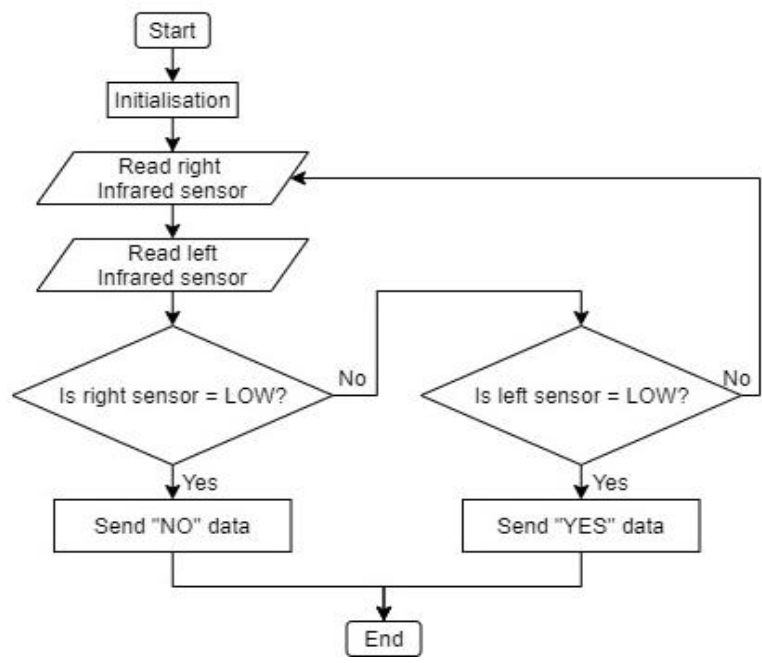

(b)

Figure 6. Work flow diagram of; (a) measurement for body height and (b) hand gesture detection 


\subsection{Anamnesis process}

In this robotic assistant, anamnesis is the main process is carried out automatically in the third phase of the operation. This process is performed by asking user questions about their health conditions and the history of their involvement with people affected by the COVID-19 virus. Users who are given this treatment are male and female at the age of 20 to 30 years. Questions are raised on the monitor screen and the user is required to answer yes or no by waving his/her left or right palm in front of the hand gesture sensor.

\subsection{Desktop application}

The work of this application is based on the functional process described in Figure 2 using Python programming. First, this application instructs the microcontroller to detect the user's presence in front of the screen. If detected, the system will move to the second stage, namely scanning the user's ID card from which user data is obtained automatically. In the third stage, measurement of the user's body temperature, weight, and height will take place and the dataset will be stored in an array.

The fourth stage is anamnesis process that involves user interaction using hand gestures. A total of 10 questions will be asked to the user visually on the monitor screen. On each question, the application commands the microcontroller to perform hand gesture detection. If a left-hand gesture is detected, then the answer is yes, the high (or 1) value of binary data will be stored in an array, and vice versa. In the final stage, an anamnesis algorithm will be performed to determine the end-user status using the binary data configuration obtained. The application will automatically generate report containing actual data and user status in a PDF form. Then the file will be sent to the medical operator's email.

\subsection{Sensor characterization}

This characterization is implemented on three sensors; MLX90614 sensor module for measuring body temperature without contact, load cell with HX711 module for measuring body weight, and VL5311x for measuring height. The measurement outputs from these three sensors are compared with that of respective standard measuring instrument. After both the test value and the standard value are obtained, a regression equation is created that connects the test and standard values. Standard devices used herein are Infrared Thermometer from Nankai for measuring body temperature; HN-289 from omron for measuring body weight; and SH-2A, stature meter from GEA for measuring body height. The regression equations for each body measurement described in (1), (2), and (3):

$$
\begin{aligned}
& y_{\text {temp }}=0.97 x_{\text {temp }}+1.28 \\
& y_{\text {weight }}=x_{\text {weight }}+0.63 \\
& y_{\text {height }}=-1.15 x_{\text {height }}+205.36
\end{aligned}
$$

To test the precision, each sensor is calibrated with a standard measuring medium. The standard measuring instrument is also calibrated in similar way. This test was repeated ten times on a person with a measured body temperature of $36 \pm 0.2^{\circ} \mathrm{C}$, a height of $168 \pm 3.2 \mathrm{~cm}$, and a bodyweight of $66.3 \pm 1.9 \mathrm{~kg}$. To test the accuracy, each sensor is calibrated with a different object. The same test is also performed onto 31 people using standard measuring instruments as a comparison.

\section{RESULT AND DISCUSSION}

\subsection{Vital signs reading}

This test is carried out to callibrate the sensor. The test done for the same distance, $+30 \mathrm{~cm}$ from the forehead of the respondents, on both the installed Thermopile MLX90614 sensor and the standard infrared thermometer. For accuracy test, the measurements of body temperature have a maximum error of $0.78 \%$, Figure 7 (a). A standard deviation of 0.3 is obtained for the precision factor of the body temperature measurements, depicted in Figure 7 (b). The second measurement is the respondent's body weight using four load cell sensors, with a maximum load capacity of $200 \mathrm{~kg}$, placed at corners of the stepping frame at a distance of $20 \mathrm{~cm}$ from the center of mass.

The accuracy factor test in shows that the measurements of body weight have a maximum error of $3.48 \%$, Figure 8 (a). The precision of the body weight measurements, as shown in Figure 8 (b), produces a standard deviation of 13.4. For height measurement test, the user's height measurement results from ARTA-1 are compared with the actual height measured manually.

In terms of accuracy factor, Figure 9 (a) shows that the measurement of body height parameters has a maximum error of $10.1 \%$, while its precision factor exhibits a standard deviation of 5.08, Figure 9 (b). As can be seen in Table 1, the body temperature measurement performance is excellent with an accuracy and precision of more than $99 \%$. Error in body weight measurement maybe due to the position of the stepping

The application of instrumentation system on a contactless robotic triage assistant... (Niko Azhari Hidayat) 
frame does not fit exactly with the center of mass, which makes the respondent does not step directly on the sensor for accurate and precise measurements by the system. Lack of accuracy and precision in body height measurement is likely due to the sensor laser beam does not hit the end of the user's head when measurement happened. The lighting condition, i.e. reflections from surrounding may distub the laser beam path, hence affects the accuracy of sensor readings.

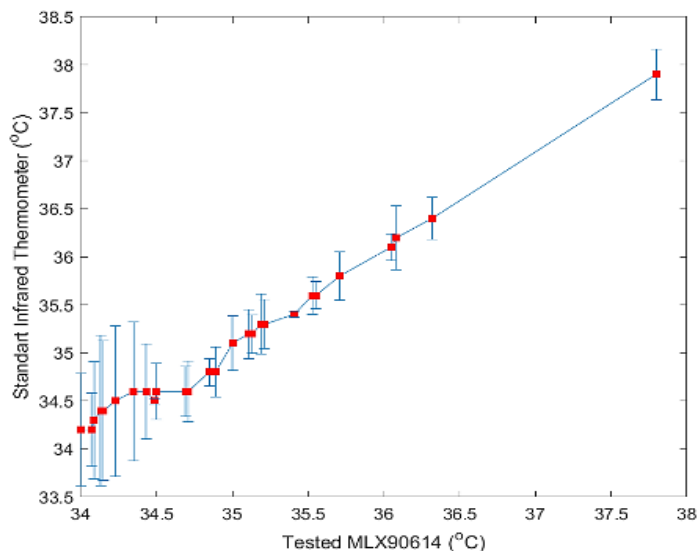

(a)

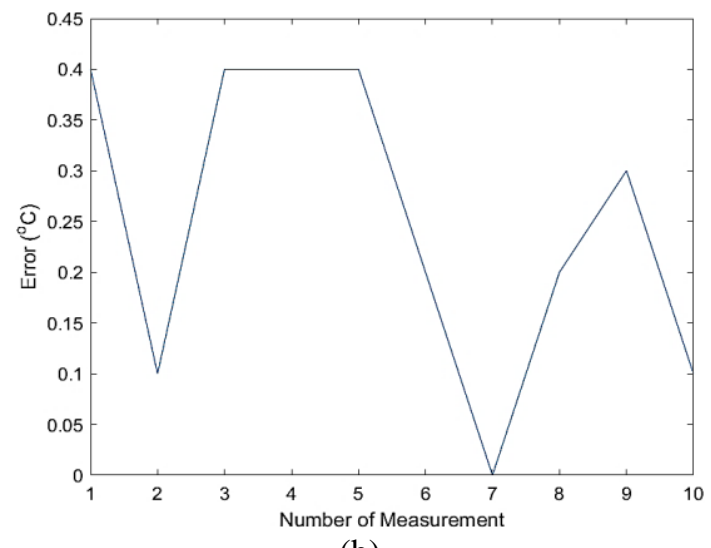

(b)

Figure 7. Test for body temperature measurement; (a) accuracy test, (b) precision test

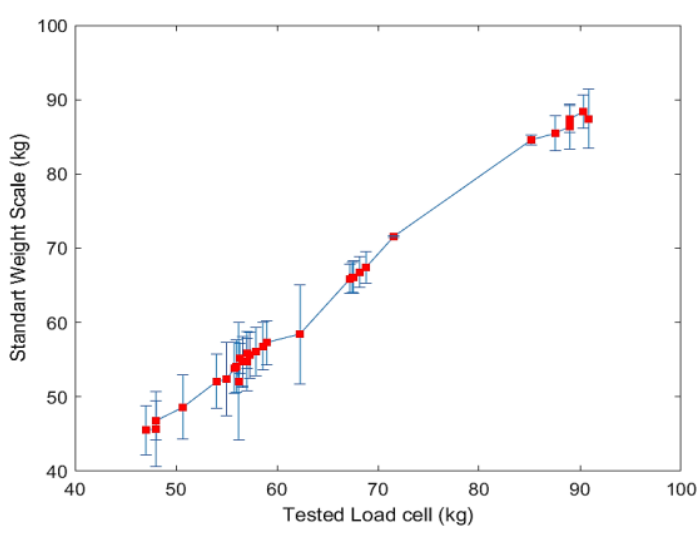

(a)

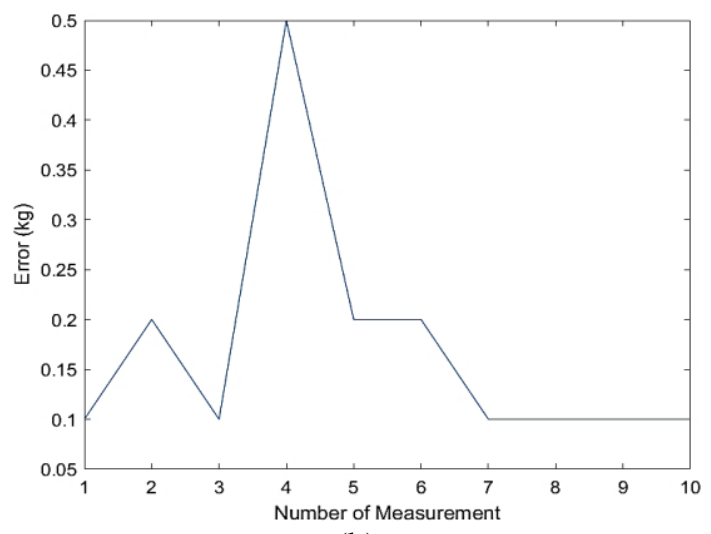

(b)

Figure 8. Body weight measurement; (a) accuracy test, (b) precision test

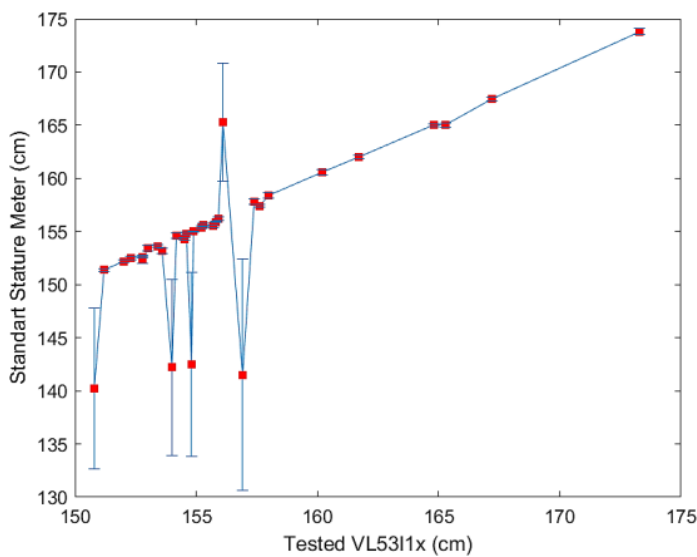

(a)

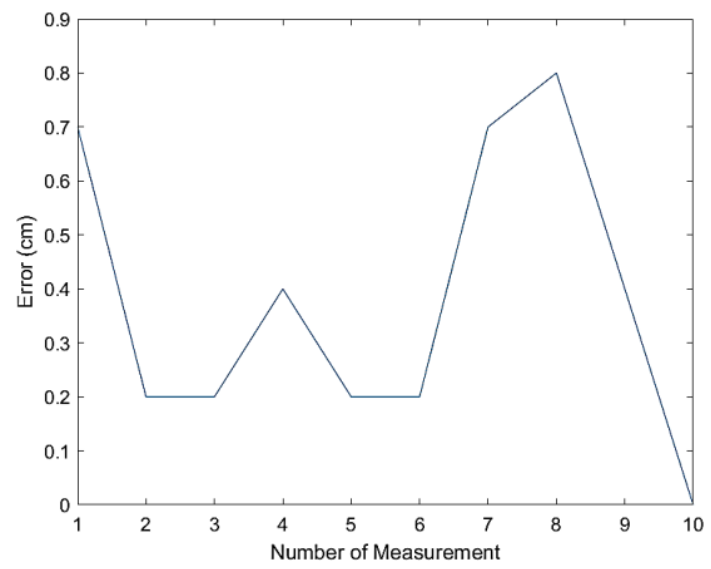

(b)

Figure 9. Accuracy test for body height measurement; (a) accuracy test and (b) precision test 
Table 1. Accuracy and precision test result

\begin{tabular}{cccccc}
\hline Measurement & Sensor & Average error & Accuracy $(\%)$ & Standart deviation & Precision $(\%)$ \\
\hline Body temp. & Thermopile MLX90614 & 0.36 & 99.44 & 0.30 & 99.70 \\
Body weigth & Load cell & 3.48 & 96.52 & 13.4 & 86.60 \\
Body height & V1531x & 1.47 & 98.53 & 5.08 & 94.92 \\
\hline
\end{tabular}

\subsection{Hand gesture reading}

As mentioned in the previous section, the hand gesture detection feature is used in the anamnesis process for the users to answer ten anamnesis questions without touching the ARTA-1 machine, simply by waving his/her palm to the right or left, instead. Testing the two distant sensors was carried out successfully to ensure that the detection can be made at a distance of of less than $18 \mathrm{~cm}$ from the sensors. The gesture speed must also be relatively slow to be detected. With these sensors, detection of hand gesture reach $100 \%$ of accuracy.

\subsection{Overall operational device}

The robotic triage assistant (ARTA-1) is powered by $220 \mathrm{~V} \mathrm{AC}$ and uses a UPS unit to protect the entire device from a sudden power failure. The core of this device is a computer that supply powers to all microcontroller and sensor boards to run the triage application as depicted in Figure 3. User interface (UI) design is made to be informative and attractive to users, including the placement of all sensors also provides convenience for users Figure 10. Further, all information related to user data and triage results will be sent and stored to medical personnel automatically. All these will certainly make the work of medical personnel easier and reduce the risk of transmitting the COVID-19 from patients to medical personnel and vice versa.

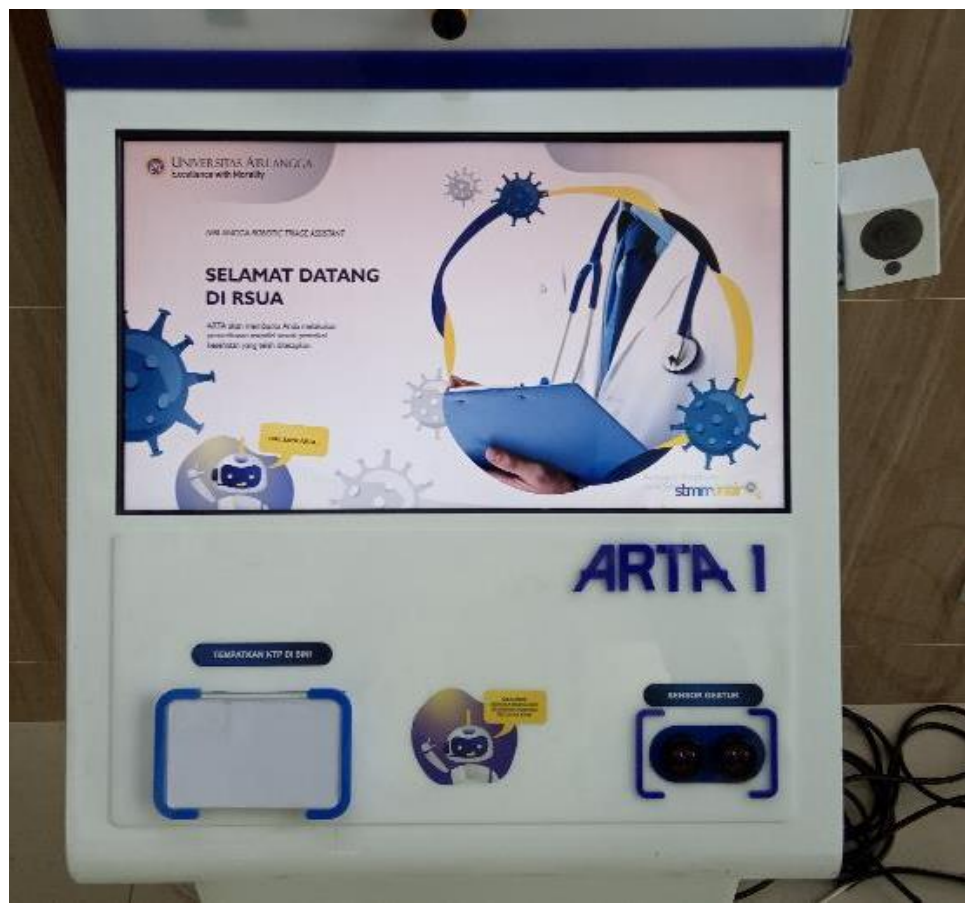

Figure 10. User interface display for ARTA-1

\section{CONCLUSION}

The design of the instrumentation system on the robotic triage assistant (ARTA-1) has fairly good performances. Measurements of body temperature have an accuracy and precision of over $99 \%$. Bodyweight measurements provide a modest precision at $86.60 \%$, with a fairly high accuracy of $96.52 \%$. Bodyweight measurements also showcase a good performance with an accuracy of $98.53 \%$ and a precision of $94.92 \%$. A pair of distant sensors, used in detecting hand gestures during anamnesis process, show a smooth performance at a radius of less than $18 \mathrm{~cm}$. The use of these sensors have been adopted based on the need for safe, comfortable, and touch-free triage checking for COVID-19 suspects to ease the work of medical personnel and reduce the risk of COVID-19 transmission. 


\section{ACKNOWLEDMENT}

This triage robot development research program is intended for handling the COVID-19 outbreak. This program was launched by Universitas Airlangga by involving all experts from the Faculty of Advanced Technology and Multidiscipline. We would like to thank the Chancellor of Airlangga University for his support for the successful implementation of this research program.

\section{REFERENCES}

[1] Kementerian Riset dan Teknologi, "Kemenristek/BRIN Research and Engineer's Innovation Catalog to Overcome the Pandemic (in Indonesian: Katalog Inovasi Karya Peneliti dan Perekayasa Kemenristek/BRIN untuk Mengatasi Pandemi)," Jakarta: Kementerian Riset dan Teknologi, 2020.

[2] M. A. Shereen, S. Khan, A. Kazmi, N. Bashir, and R. Siddique, "COVID-19 infection: Origin, transmission, and characteristics of human coronaviruses," J. Adv. Res., vol. 24, pp. 91-98, 2020, doi: 10.1016/j.jare.2020.03.005.

[3] F. E. Ejeh, S. Owoicho, A. S. Saleh, L. Madukaji, and K. O. Okon, "Factors associated with preventive behaviors, anxiety among healthcare workers and response preparedness against COVID-19 outbreak: A one health approach," Clin. Epidemiol. Glob. Heal, vol. 10, no. December 2020, p. 100671, 2021, doi: 10.1016/j.cegh.2020.11.004.

[4] J. Greene and D. M. Gibson, "Workers at long-term care facilities and their risk for severe COVID-19 illness," Prev. Med. (Baltim)., vol. 143, no. July 2020, p. 106328, 2021, doi: 10.1016/j.ypmed.2020.106328.

[5] E. Temkin et al., "Extremely low prevalence of asymptomatic COVID-19 among healthcare workers caring for COVID-19 patients in Israeli hospitals: a cross-sectional study," Clin. Microbiol. Infect., vol. 27, no. 1, pp. 1-4, 2020, doi: 10.1016/j.cmi.2020.09.040.

[6] Y. Wu et al., "Validation of the COVID-19 Fears Questionnaires for Chronic Medical Conditions: A Scleroderma Patient-centered Intervention Network COVID-19 Cohort study,” J. Psychosom. Res., vol. 139, no. July, p. 110271, 2020, doi: 10.1016/j.jpsychores.2020.110271.

[7] C. Chang and R. R. Murphy, "Towards robot-assisted mass-casualty triage," 2007 IEEE Int. Conf. Networking, Sens. Control. ICNSC'07, no. March, pp. 267-272, 2007, doi: 10.1109/ICNSC.2007.372789.

[8] R. Tsumura et al., "Tele-operative Robotic Lung Ultrasound Scanning Platform for Triage of COVID-19 Patients," 2020, [Online]. Available: http://arxiv.org/abs/2010.12335

[9] C. Gigi, C. Nedelcuta, D. Bãleanu, and V. D. Constantin, “The Importance Of Anamnesis In Pediatrics," vol. 82, no. August, 2019.

[10] N. Alieva, P. Safarova, and A. Kerimov, "Clinical and anamnesis signs of hypercoagulation in patients with B-thalassemia," Hematol. Transfus. Cell Ther., vol. 42, no. S 1, pp. 44-45, 2020, doi: 10.1016/j.htct.2020.09.080.

[11] C. Claeys et al., "Anamnesis immune response and safety of an inactivated quadrivalent influenza vaccine in primed versus vaccine-naïve children," Pediatr. Infect. Dis. J., vol. 38, no. 2, pp. 203-210, 2019, doi: 10.1097/INF.0000000000002217.

[12] M. C. Moore et al., "Comparison of anamnesis responses to rabies vaccination in dogs and cats with current and out-of-date vaccination status," J. Am. Vet. Med. Assoc., vol. 246, no. 2, pp. 205-211, 2015, doi: 10.2460/javma.246.2.205.

[13] G. Marques and R. Pitarma, "Non-contact infrared temperature acquisition system based on internet of things for laboratory activities monitoring," Procedia Comput. Sci., vol. 155, pp. 487-494, 2019, d oi: 10.1016/j.procs.2019.08.068.

[14] H. Guo, M. Ferrara, J. Coleman, M. Loyola, and F. Meggers, "Air temperature and mean radiant temperature data, collected and simulated across a radiantly-heated high-bay laboratory,” Data Br., vol. 30, p. 105192, 2020, doi: 10.1016/j.dib.2020.105192.

[15] H. Liu and C. Lee, "A Low-Complexity Synchronizer," IEEE Transactions on Circuits and Systems II: Express Briefsvol, 53, no. 11, pp. 1269-1273, 2006, doi: 10.1109/TCSII.2006.882804.

[16] Y. H. Bolaños, C. F. Rengifo, P. E. Caicedo, L. E. Rodriguez, and W. A. Sierra, "Electronic system for step width estimation using programmable system-on-chip technology and time of flight cameras," HardwareX, vol. 8, 2020, doi: 10.1016/j.ohx.2020.e00126.

[17] P. Megantoro, Y. D. Nugroho, F. Anggara, A. Pakha, and B. A. Pramudita, "The implementation of genetic algorithm to MPPT technique in a DC/DC buck converter under partial shading condition," Proc. - 2018 3rd Int. Conf. Inf. Technol. Inf. Syst. Electr. Eng. ICITISEE 2018, 2018, pp. 308-312, doi: 10.1109/ICITISEE.2018.8721005.

[18] Iswanto, P. Megantoro, B. A. Pramudita, and H. A. Winarno, "Wi-fi Communication Methods for Internet of Things-based Sensor Telemetry with a Visual Basic-based User Interface," pp. 263-266, 2020, doi: 10.1109/icitacee50144.2020.9239162.

[19] T. Triwiyanto, I. P. A. Pawana, B. G. Irianto, T. B. Indrato, and I. D. G. H. Wisana, "Embedded system for upperlimb exoskeleton based on electromyography control," TELKOMNIKA Telecommunication Computing Electronics and Control, vol. 17, no. 6, pp. 2992-3002, 2019, doi: 10.12928/TELKOMNIKA.v17i6.11670.

[20] T. P. Tunggal, S. A. Juliani, H. A. Widodo, R. A. Atmoko, and P. T. Nguyen, "The Design of Digital Heart Rate Meter Using Microcontroller," J. Robot. Control, vol. 1, no. 5, pp. 141-144, 2020, doi: 10.18196/jrc.1529.

[21] S. S. Mohammed Sheet, and M. S. Jarjees, "Microcontroller based in vitro hematocrit measurement system," Indones. J. Electr. Eng. Comput. Sci., vol. 18, no. 2, pp. 717-723, 2020, doi: 10.11591/ijeecs.v18.i2.pp717-723.

[22] A. G. Shabeeb, A. J. Al-Askery, and Z. M. Nahi, "Remote monitoring of a premature infants incubator," Indones. J. Electr. Eng. Comput. Sci., vol. 17, no. 3, pp. 1232-1238, 2019, doi: 10.11591/ijeecs.v17.i3.pp1232-1238. 
[23] N. A. A. Rahman and A. B. Jambek, "Biomedical health monitoring system design and analysis," Indones. J. Electr. Eng. Comput. Sci., vol. 13, no. 3, pp. 1056-1064, 2019, doi: 10.11591/ijeecs.v13.i3.pp1056-1064.

[24] P. Megantoro and H. A. Winarno, "EKA v1: Emergency Call Auto-register, an Emergency Warning System based on Internet of Things for Intensive Care Patient at Hospital," IOP Conf. Ser. Mater. Sci. Eng., vol. 835, no. 1, 2020, doi: 10.1088/1757-899X/835/1/012033.

[25] B. G. Irianto, Budhiaji, and D. H. Andayani, "A low-cost electro-cardiograph machine equipped with sensitivity and paper speed option," TELKOMNIKA Telecommunication Computing Electronics and Control, vol. 17, no. 3, pp. 1275-1281, 2019, doi: 10.12928/TELKOMNIKA.V17I3.8558.

[26] D. Gupta, A. Parikh, and R. Swarnalatha, "Integrated healthcare monitoring device for obese adults using internet of things (IoT),” Int. J. Electr. Comput. Eng., vol. 10, no. 2, p. 1239, 2020, doi: 10.11591/ijece.v10i2.pp1239-1247.

[27] M. A. Al-Dhaheri, N. E. Mekkakia-Maaza, H. Mouhadjer, and A. Lakhdari, "Noninvasive blood glucose monitoring system based on near-infrared method," Int. J. Electr. Comput. Eng., vol. 10, no. 2, pp. 1736-1746, 2020, doi: 10.11591/ijece.v10i2.pp1736-1746.

[28] N. S. Ali, Z. A. A. Alyasseri, and A. Abdulmohson, "Real-Time Heart Pulse Monitoring Technique Using Wireless Sensor Network and Mobile Application," Int. J. Electr. Comput. Eng., vol. 8, no. 6, p. 5118, 2018, doi: 10.11591/ijece.v8i6.pp5118-5126.

[29] K. Bhagchandani and D. Peter Augustine, "IoT based heart monitoring and alerting system with cloud computing and managing the traffic for an ambulance in India," Int. J. Electr. Comput. Eng., vol. 9, no. 6, pp. 5068-5074, 2019, doi: 10.11591/ijece.v9i6.pp5068-5074.

[30] N. A. Zakaria, N. A. Rashid, and M. A. Asa'ari, "Development of fall risk detector for elderly," TELKOMNIKA Telecommunication Computing Electronics and. Control, vol. 16, no. 4, pp. 1577-1582, 2018, doi: 10.12928/TELKOMNIKA.v16i4.9066.

\section{BIOGRAPHIES OF AUTHORS}
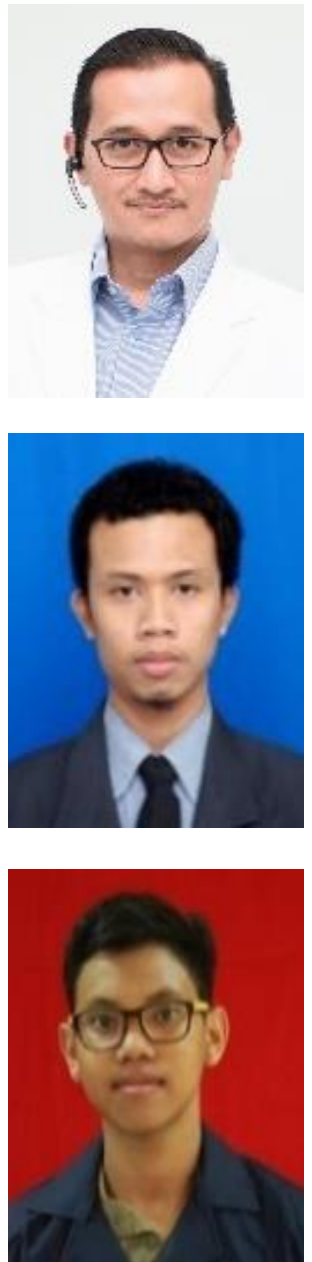

Niko Azhari Hidayat is a secretary in Institute for Research \& Community Service and also lecturer in Electrical Engineering, School of Advanced Technology, and Multidisciplinary, Universitas Airlangga. He received a bachelor's degree of medical from Universitas Udayana. $\mathrm{He}$ is also the founder and conceptor of Vascular Indonesia: National Telehealth Platform. His speciality is in cardiothoracic and vascular surgery.

Prisma Megantoro is a lecturer in Electrical Engineering, School of Advanced Technology, and Multidisciplinary, Universitas Airlangga since 2020. He received a bachelor's degree and master's degree from Universitas Gadjah Mada, Yogyakarta, Indonesia in 2014 and 2018. His current research is focused on solar photovoltaic technology, embedded system, and the internet of things.

Abdufattah Yurianta is a student in Biomedical Engineering, Faculty of Science and Technology, Airlangga University, since 2018. He born in Surabaya, 5 September 2000, and lived in Surabaya since then. He focused on medical instrumentation. 


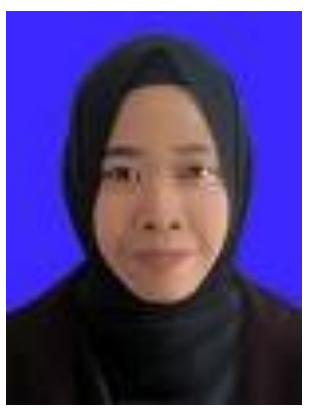

Amila Sofiah is a lecturer in Robotics Engineering and Artifial Intelligence, School of Advanced Technology, and Multidisciplinary, Universitas Airlangga since 2020. She received a bachelor's degree from Universitas Airlangga and a master's degree from Institut Teknologi Sepuluh Nopember, Surabaya, Indonesia in 2015 and 2018. Her current research is focused on Biomedical Signal Processing, Instrumentation \& Control, Robotics.

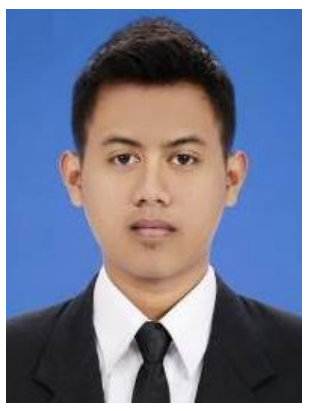

Shofa Aulia Aldhama is a lecturer in Industrial Engineering, School of Advanced Technology, and Multidiscipline, Universitas Airlangga since 2020. He received a bachelor's degree from Universitas Brawijaya and a master's degree from Institut Teknologi Sepuluh Nopember, Surabaya, Indonesia in 2015 and 2018. His current research is focused on ergonomic design.

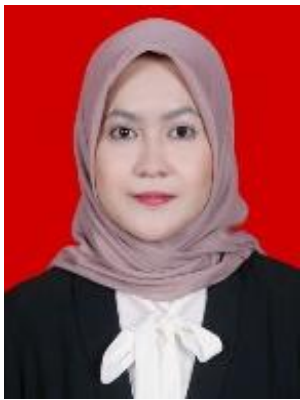

Yutika Amelia Effendi is a lecturer in Robotics Engineering and Artificial Intelligence, Faculty of Advanced Technology and Multidiscipline, Universitas Airlangga since 2020. She received a bachelor's and master's degree in Informatics/Computer Science Institut Teknologi Sepuluh Nopember, Surabaya, Indonesia (in 2016 and 2018). Her current research is focused on Business Process Management and Modeling, Process Mining, Process Discovery, Optimization, IT Governance, Knowledge Engineering, Enterprise Resource Planning. 